Journal of Patient-Centered

Volume 2

Issue 3 - Vascular Disease

Article 6

8-14-2015

\title{
Type II Endoleak Following Endovascular Repair of Infrarenal Abdominal Aortic Aneurysm: Innovative Transgraft Approach to Contemporary Management
}

M. Fuad Jan

Mark W. Mewissen

Follow this and additional works at: https://aah.org/jpcrr

Part of the Cardiology Commons, and the Cardiovascular Diseases Commons

\section{Recommended Citation}

Jan MF, Mewissen MW. Type II endoleak following endovascular repair of infrarenal abdominal aortic aneurysm: innovative transgraft approach to contemporary management. J Patient-Centered Res Rev. 2015;2:118-126. doi: 10.17294/2330-0698.1202

Published quarterly by Midwest-based health system Advocate Aurora Health and indexed in PubMed Central, the Journal of Patient-Centered Research and Reviews (JPCRR) is an open access, peer-reviewed medical journal focused on disseminating scholarly works devoted to improving patient-centered care practices, health outcomes, and the patient experience. 


\title{
Type II Endoleak Following Endovascular Repair of Infrarenal Abdominal Aortic Aneurysm: Innovative Transgraft Approach to Contemporary Management
}

\author{
M. Fuad Jan, MBBS, MD, Mark W. Mewissen, MD \\ Aurora Cardiovascular Services, Aurora Sinai/Aurora St. Luke's Medical Centers, Milwaukee, WI
}

\begin{abstract}
Elective endovascular aneurysm repair (EVAR) is the first-line therapeutic option for patients with infrarenal abdominal aortic aneurysm. However, endoleaks - persistent blood flow outside the lumen of the stent graft (or endograft) but within the aneurysm sac or adjacent vascular segment being treated by the graft - continue to be a persistent problem in the post-EVAR setting. The type II endoleak is the most common of these and can be a demanding challenge to address by standard endovascular techniques. Currently, two prominent endovascular techniques exist for the management of type II endoleaks: direct translumbar embolization and transarterial embolization. Both of these are fraught with their own limitations and complications. In this review, we describe the contemporary trends in management of type II endoleaks and introduce a novel endovascular technique to treat this challenging and common EVAR complication.
\end{abstract}

Keywords endovascular aortic repair, endoleak, transgraft embolization, Onyx liquid embolic agent

Elective endovascular aneurysm repair (EVAR) has emerged as the first-line therapeutic option for patients with infrarenal abdominal aortic aneurysms $(\mathrm{AAA})^{1-3}$ that have a diameter of at least $5.0-5.5 \mathrm{~cm}$. This is because all-cause perioperative mortality, as well as AAA-related mortality at short- and intermediate-term follow-up, is lower in EVAR than open surgical repair. ${ }^{4}$ Although beset with a spectrum of complications that have no surgical counterparts (Box 1), the most common and often challenging complication is the endoleak, defined by persistent blood flow outside the lumen of the stent graft (or endograft) but within the aneurysm sac or adjacent vascular segment being treated by the graft. An endoleak usually is evidence of incomplete exclusion of the aneurysm from the circulation with resulting elevated systemic pressures in the aneurysm sac. Endoleaks are traditionally classified into types I through IV, with types I and III often requiring

Correspondence: Mark W. Mewissen, MD, 2801 W. Kinnickinnic River Parkway, Suite 330, Milwaukee, WI, 53215, T: 414-385-2429, F: 414-385-2461, Email: mark.mewissen@aurora.org immediate reintervention because they are associated with a high risk of aneurysm rupture. ${ }^{2}$ A complex array of factors - device construction, collateral pattern, amount of aneurysmal clot, spontaneous thrombosis and secondary interventions - influence the incidence of endoleaks.

\section{Box 1. Complications post-endovascular aneurysm repair}
1. Endoleak
2. Endograft infection
3. Endograft thrombosis
4. Endograft migration
5. Peripheral microembolism
6. Access site bleeding/hematoma
7. Late rupture

Figure 1 outlines the types of endoleaks based on information regarding the course of blood flow into the aneurysm sac. As shown, a type II endoleak (T2E) - the most common endoleak encountered post-EVAR - is due to persistent retrograde blood flow from aortic side branches, such as the inferior 


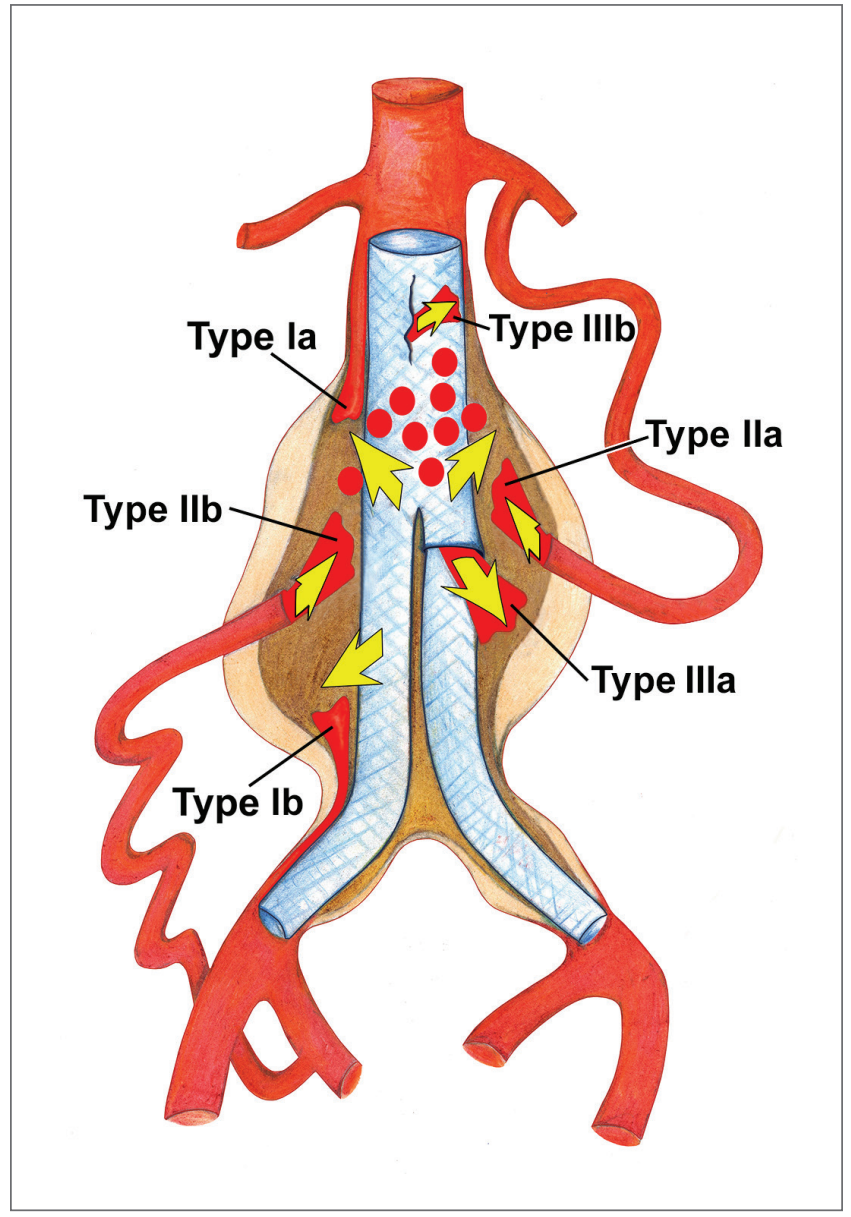

mesenteric artery (type IIa, 33\%), lumbar arteries (type IIb, 64\%) or other collateral blood vessels (accessory renal arteries, internal iliac arteries, gonadal, median sacral artery, $3 \%$ ), into the perigraft space (aneurysm sac). Incidence of post-EVAR T2E has been identified in the range of $10.2-45 \%,{ }^{5-8}$ varying according to the sensitivity of the diagnostic method used. These leaks typically are found during routine ultrasound or computed tomography (CT) follow-up for EVAR.

Although most T2Es resolve spontaneously within a few months or remain benign, ${ }^{9-12}$ persistent T2Es can be associated with sac expansion and, therefore, require secondary intervention ${ }^{10}$ to avoid rupture. Currently, two major endovascular techniques exist for the management of T2Es: direct translumbar embolization (TLE) and transarterial embolization (TAE). TLE is believed to be more effective for treating a $T 2 E^{13}$ because the technique allows for direct needle access into the aneurysm sac as close as possible to the "nidus of the leak," which can then be eliminated more
Figure 1. Schematic for the classification of endoleaks. A type I endoleak indicates persistent "perigraft" channel(s) of blood flow caused by an inadequate sealing at the proximal (type la) or distal (type lb) end of the endograft. In the case of an aortomonoiliac prosthesis, a type I endoleak also may refer to blood flow around an iliac occluded plug (type Ic). A type II endoleak is due to retrograde blood flow, or "retroleak," from a single vessel (usually the inferior mesenteric artery - type Ila), lumbar arteries (type IIb - two vessels or more) or other collateral blood vessels. Endoleaks caused by disconnection of a component of the endograft are classified as type IIla (junctional separation of the modular components) or type IIIb if caused by fabric tear, fabric disruption or disintegration of the graft material. Based on size, these endoleaks are further subdivided as major ( $>2$ $\mathrm{mm}$ ) or minor (<2 mm). A type IV endoleak is caused by blood flow through an intact but otherwise porous fabric material of the endograft and, by definition, is classified as type IV only if detected within the first month after endovascular aneurysm repair. An endoleak visualized by imaging studies but without precise identification of the source is classified as one of undefined origin. Some authors also use the term type $V$ endoleak for endotension, a poorly understood phenomenon in which there is continued expansion of the aneurysm sac without evidence of a true leak site.

effectively, analogous to central nidus embolization of an arteriovenous malformation. The challenge of this technique lies in precise advancement and positioning of the needle, using either fluoroscopy or CT as the guiding modality. There are many instances in which TLE is not feasible because of the location of the endoleak relative to the inferior vena cava, bowel loops or kidney, or its location in the pelvis, where safe needle access is not possible due to surrounding bony structures.

In this report, we first describe a novel transgraft embolization (TGE) technique that utilizes laser energy to micropuncture the endograft via a transfemoral arterial approach, allowing access to the aneurysm sac at the precise site of the endoleak nidus irrespective of its location. A review of the recent literature on EVAR of infrarenal AAA follows to put this innovative technique into context with contemporary standards of care. 

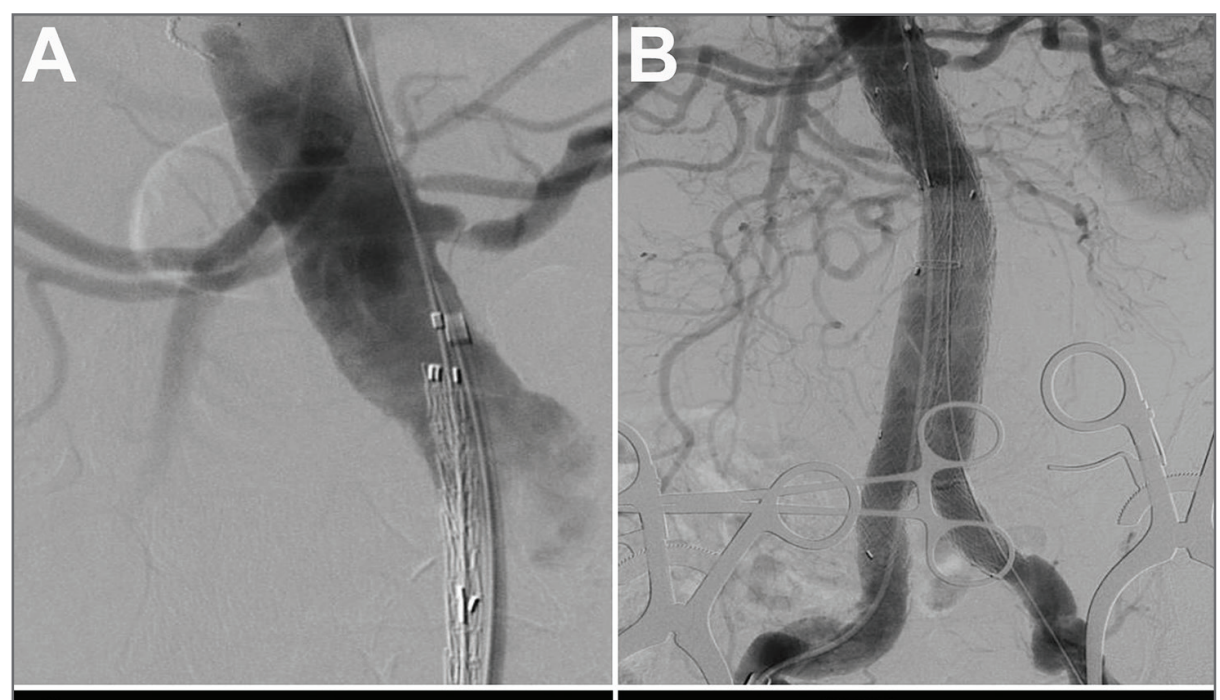

Figure 2. Composite aortograms and computed tomography angiographic (CTA) views of the abdominal aorta of a 79-yearold man with several vascular disease risk factors. A: Aortogram obtained prior to endovascular aneurysm repair (EVAR) of a 6-cm infrarenal abdominal aortic aneurysm (AAA). B: Aortogram obtained immediately postEVAR procedure demonstrating no endoleak and a well-positioned endoprosthesis. C: Follow-up CTA obtained 1 month
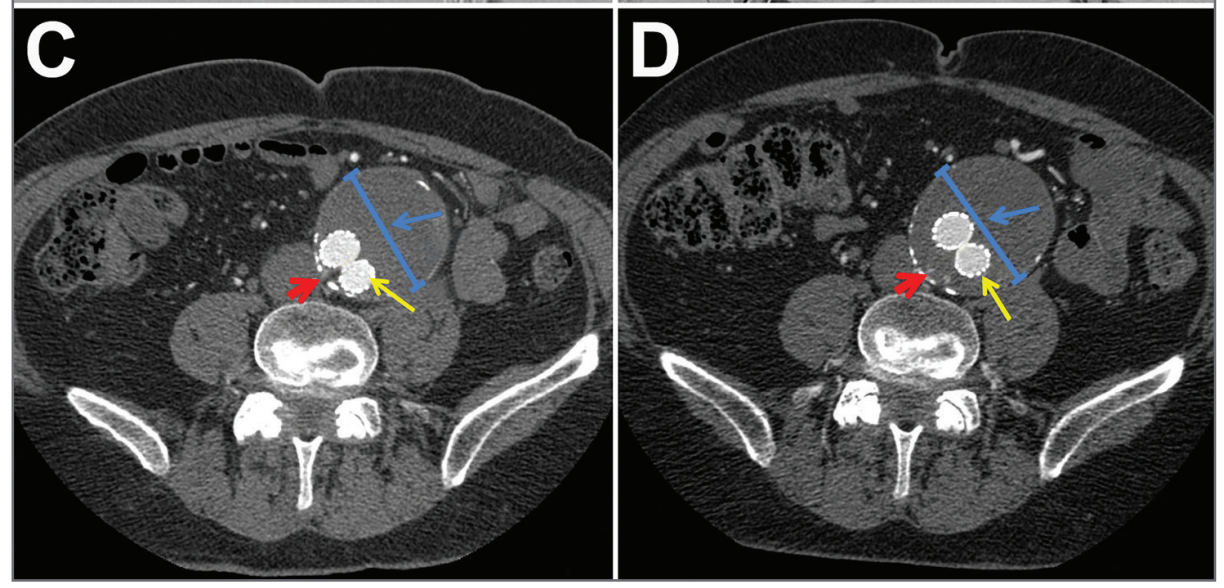
after EVAR (endoprosthesis indicated by yellow arrow) revealing a small type II endoleak (red arrow). Also shown is an aneurysm sac with a diameter of $6.2 \mathrm{~cm}$ (blue bar/arrow). D: Follow-up CTA at 18 months demonstrating aneurysm sac growth to $7.4 \mathrm{~cm}$ (blue bar/arrow) with a persistent type II endoleak (red arrow). At this stage, a decision was made to intervene on the endoleak.

\section{CASE DESCRIPTION}

A 79-year-old man with a history of hypertension, dyslipidemia, diabetes mellitus and stable coronary heart disease had undergone successful EVAR for infrarenal AAA with a Gore $^{\circledR}$ Excluder $^{\circledR}$ AAA Endoprosthesis (W. L. Gore \& Associates Inc., Flagstaff, AZ) (Figure 2A/2B). Routine post-EVAR $\mathrm{CT}$ scan at 1-month screening revealed a mild T2E (Figure 2C, red arrow) with an aneurysm sac diameter of $6.2 \mathrm{~cm}$ (Figure 2C, blue bar). However, a follow-up CT scan 18 months post-EVAR showed aneurysm sac growth to $7.4 \mathrm{~cm}$ with a persistent T2E (Figure 2D). Although addressing this patient's T2E using TLE was considered, detailed CT evaluation showed this approach would be complicated by the neighboring pelvic bony structures as well as the inferior vena cava. Thus, we decided to approach the T2E with our novel TGE technique.

\section{Procedure}

After detailed analysis (CT reconstruction) of the CT angiogram (Figure 2D and Figure 3A), taking into account the location of the $\mathrm{T} 2 \mathrm{E}$ with respect to the limbs of the endoprosthesis, we determined that the right limb of the endoprosthesis provided the most immediate access to the endoleak. Following percutaneous catheterization of the right common femoral artery using ultrasound to determine patency and guide needle entry, a 6 -French $20-\mathrm{cm}$ sheath was advanced over a standard 0.038 -inch guidewire. This was followed by the introduction of an angiographic catheter (Soft-Vu ${ }^{\circledR}$ Omni Flush, AngioDynamics, Latham, NY) at the level of the superior mesenteric artery to obtain an aortogram (Figure 3B) in order to rule out a type Ia leak and, importantly, study late arterial filling of the type II leak, which can be supplied by superior mesenteric artery collaterals. Through the sheath, a 6-French internal mammary artery coronary 


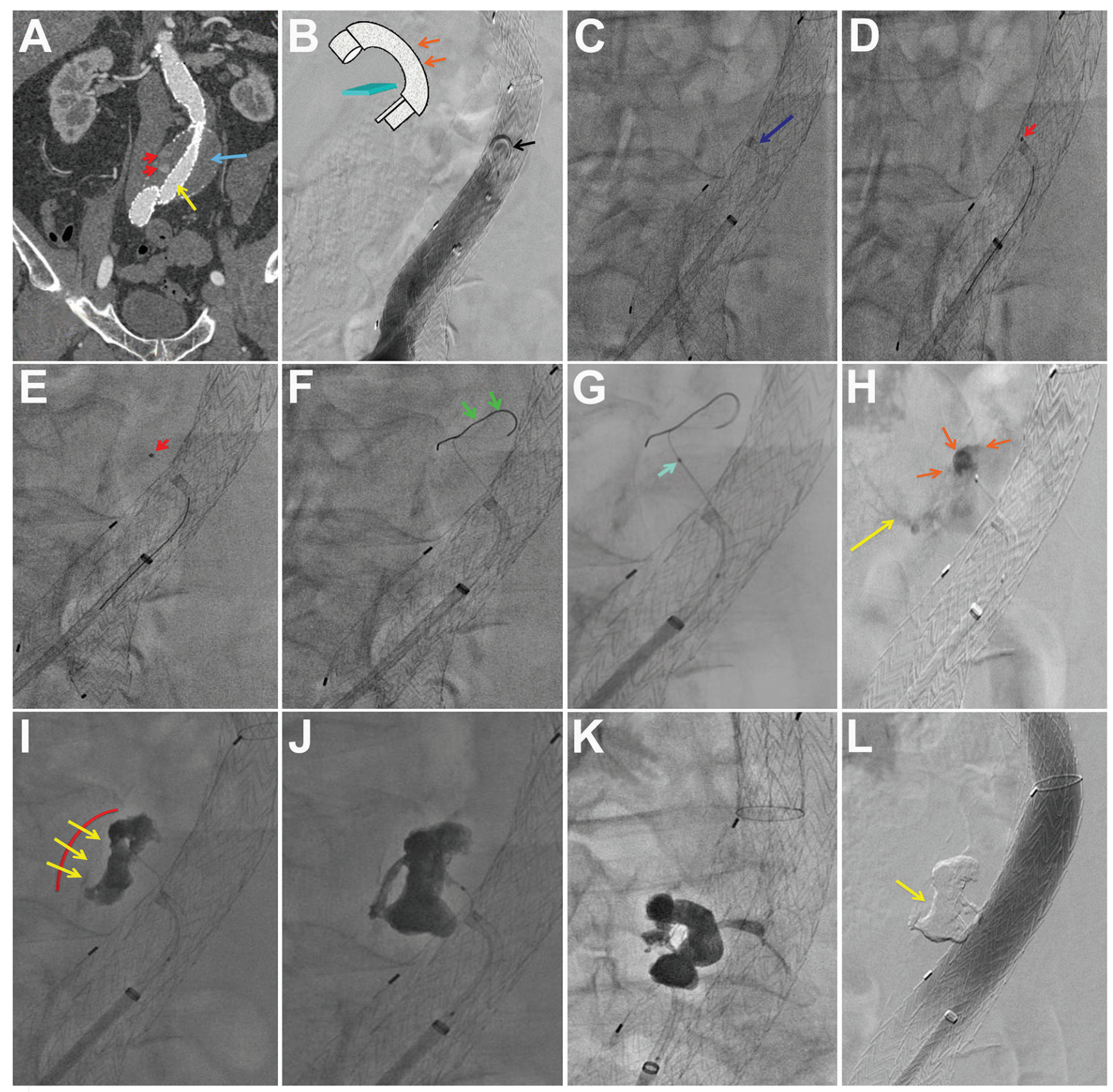

Figure 3. This angiographic collage depicts the transgraft embolization (TGE) technique used for management of a type II endoleak (T2E) in a 79-year-old patient with aneurysm sac growth up to $7.4 \mathrm{~cm}$ post-endovascular aneurysm repair. A: Outlay of the aneurysm sac (blue arrow), endoprosthesis (yellow arrow) and T2E (small red arrows). Computed tomography (CT) angiogram precisely localizes the position of the endoleak nidus. Based on this, the operator is able to determine the vascular approach (right or left limb of the endograft) to precisely puncture the endograft. B: Right anterior oblique aortogram (with red arrows depicting angulation of the fluoroscopic $C$-arm based on previous CT localization) obtained with an omniflush catheter (black arrow). Often, additional angiography is performed with the catheter close to the hypogastric artery, which will generally connect to the leak via lumbar collaterals. C-E: Progressive advancement of the Turbo-Elite ${ }^{\mathrm{TM}}$ catheter (Spectranetics Corp., Colorado Springs, CO) to puncture the graft material precisely at the site of the endoleak (blue arrow = internal mammary artery catheter, red arrows $=$ Turbo-Elite). A radiopaque marker is located on the distal end of the laser catheter to aid localization. F: Advancement of the 0.014inch guidewire (green arrows) into the aneurysm sac. G: Introduction of the 2.4-French microcatheter (Echelon ${ }^{\mathrm{TM}}$, ev3 Endovascular Inc., Plymouth, MN) over the guidewire into the aneurysm sac (arrow). H-L: Successive steps in the administration of Onyx 18 (ev3 Neurovascular) (orange arrows) through the microcatheter to obliterate the T2E at the level of the nidus. In Panel $L$, the stent-graft limb is seen after the removal of the microcatheter. Note the absence of contrast extravasation at the puncture site. 


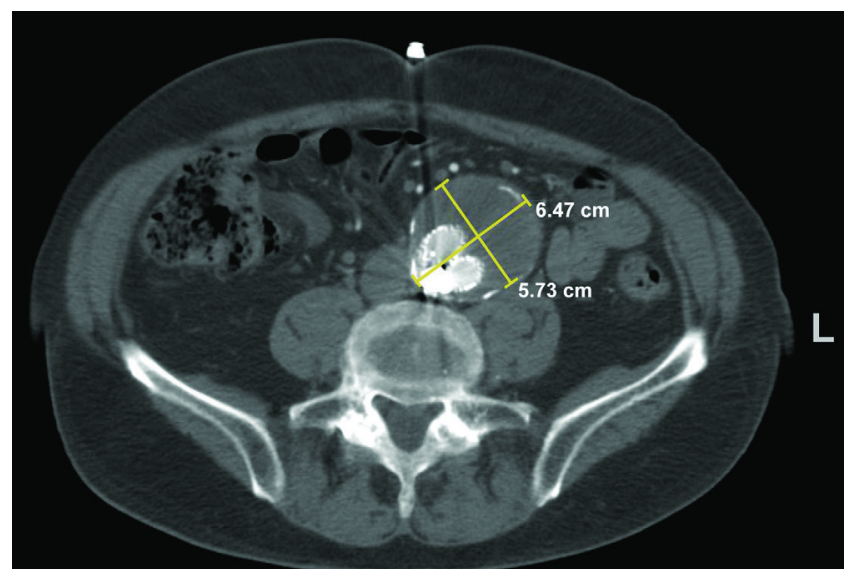

Figure 4. Computed tomographic angiography (CTA) obtained 1 year after embolization shows sustained success. Note sac regression (approximately $6.4 \mathrm{~cm}$ ) compared to preembolization CTA $(7.4 \mathrm{~cm}$, Figure 2D).

guide catheter was advanced to the level of the proximal limb of the endograft (Figure 3C, blue arrow). In the right anterior oblique 30-degree projection, the graft material was punctured successfully using a $0.9-\mathrm{mm}$ coronary laser probe (Turbo-Elite ${ }^{\mathrm{TM}}$, Spectranetics Corp., Colorado Springs, CO) (Figure 3D/3E, red arrow) precisely at the site of the endoleak. A 0.014-inch guidewire was advanced into the aneurysm sac (Figure $3 \mathrm{~F}$, green arrows), and the probe was removed and exchanged for a 2.4-French microcatheter (Echelon ${ }^{\mathrm{TM}}$, ev3 Endovascular Inc., Plymouth, MN) (Figure 3G). Through the catheter, selective digital subtraction angiography showed the endoleak at the same level (Figure $3 \mathrm{H}$, orange arrows) and also demonstrated some unnamed vascular structures (Figure $3 \mathrm{H}$, yellow arrow). Four vials of Onyx ${ }^{\circledR} 18$ (ev3 Neurovascular, Irvine, CA) were administered through the catheter to obliterate the T2E at the level of the nidus (Figure 3I-3L). The final angiogram (Figure 3L) revealed excellent results with complete obliteration of the T2E.

One year later, the follow-up computed tomography angiogram (CTA) showed decreased aneurysm sac size (Figure 4) compared to preembolization.

\section{DISCUSSION}

\section{Natural History, Risk Factors and Surveillance of T2E Post-EVAR}

The major risk with T2Es is continued aneurysm

\section{Box 2. Risk factors for persistent type II} endoleak

1. Patent inferior mesenteric artery

2. Increased number of patent individual $L 2$, L3 and L4 lumbar arteries

3. Increased total number of patent lumbar arteries

4. Aneurysm sac without thrombus

5. Endoleaks that persist on computed tomography imaging in both arterial and delayed phases

6. Endoleak cavity $>15 \mathrm{~mm}$ in maximum diameter, $1.35 \mathrm{~cm}^{3}$ in volume

7. Endoleak cavity with feeding vessels $3.2 \mathrm{~mm}$ in diameter or larger

8. *High velocity endoleaks $(>80 \mathrm{~cm} / \mathrm{s})$

9. *Unidirectional flow in endoleak

10. *Contrast washout time from aneurysm sac $\geq 520$ seconds

*Ultrasound findings.

sac expansion and possible rupture. ${ }^{14}$ Aneurysm sac expansion is defined as growth of $5 \mathrm{~mm}$ beyond the preoperative maximal sac diameter. T2Es are not related to any specific design or material of the endograft used, ${ }^{15}$ although some risk factors for their development are identified in Box 2. A T2E may appear immediately at the time of graft implantation (primary endoleak), at the first follow-up imaging study, or months or years after EVAR. Although evaluation of the natural history of persistent endoleaks is difficult because of the varying management strategies used to address these leaks, a systematic review of 32 nonrandomized, retrospective studies found that $35.4 \%$ of T2Es resolved spontaneously, whereas $0.9 \%$ of aneurysms with isolated T2Es ruptured. ${ }^{6}$ It also is important to note that whereas a persistent $\mathrm{T} 2 \mathrm{E}$ is a significant factor for continued sac expansion, a small number of aneurysms with T2Es have been reported to rupture without sac expansion. ${ }^{6}$ Recently it was reported that there is a high incidence of secondary intervention (20\%), continued aneurysm sac growth $(37.9 \%)$ and a need for graft explantation $(8.4 \%)$ in patients with T2Es. ${ }^{16,17}$

Because of the development of endoleaks, EVAR patients require long-term surveillance with serial 
radiologic imaging. Surveillance CT scans or ultrasounds are directed toward determining: a) the integrity of the graft, b) the presence of flow within the aneurysm sac (endoleak), and c) the size of the aneurysm sac. Institutions have differing protocols for post-EVAR monitoring based on their staff's expertise with different imaging modalities. ${ }^{17,18}$ The Society for Vascular Surgery recommends triple-phase CTA at 30 days and 12 months in its published guidelines on post-EVAR surveillance. ${ }^{2}$ If the 30 -day CTA reveals an endoleak or aneurysm sac growth, a 6-month CTA is recommended. If the 30-day and 12-month CTA scans reveal no endoleak, device abnormality or aneurysm sac enlargement, annual color duplex ultrasound can be used as an alternative to CTA if performed by a skilled technician in an accredited noninvasive vascular laboratory.

CTA may not be able to identify all endoleaks (e.g. occult endoleaks) in patients with aneurysm sac growth nor all feeding vessels in patients with apparent T2Es. ${ }^{19}$ Therefore, it has been suggested that a new generation of magnetic resonance imaging (MRI) contrast agents (e.g. gadofosveset trisodium) may better detect lowflow leaks. ${ }^{17}$ However, because of its own limitations (i.e. not all endografts are compatible with MRI, not all patients can undergo MRI etc.), further studies will be needed before MRI can present a real challenge to CTA.

Pressure sensors can be implanted inside the aneurysm sac at the time of EVAR to serve as another modality to identify and monitor endoleaks. Currently, the EndoSure $^{\mathrm{TM}}$ (CardioMEMS Inc., Atlanta, GA), a resonant circuit powered by an external radiofrequency antenna, is the only pressure sensor approved by the U.S. Food and Drug Administration. ${ }^{17}$ Several studies have shown its efficacy in detecting type I and II endoleaks. ${ }^{20,21}$ Because the safety, long-term complications, efficacy and accuracy of pressure sensor use related to T2Es is under debate, this method remains an adjunct to standard imaging modalities until more clinical data is available. ${ }^{17,22,23}$

\section{Management of Type II Endoleak}

Although European guidelines for T2Es recommend reintervention in patients with increased sac diameter $\geq 10 \mathrm{~mm}$ (evidence level: $2 \mathrm{~b}$ ), ${ }^{3}$ explicit guidelines are lacking in the United States. However, most clinicians will offer reintervention for patients with T2Es who have aneurysm sac growth of $>5 \mathrm{~mm}$ or persistent endoleaks ( $>6$ months). Current imaging practices most often result in an underestimation of the size and complexity of endoleaks. The EUROSTAR study found that combined adverse outcome events (aneurysm growth, transfemoral interventions and transabdominal secondary procedures) occurred in $55 \%$ of patients with T2Es compared to $15 \%$ in patients without any leak. ${ }^{24}$ Other studies reported finding signs of previous endoleaks in post-EVAR aneurysm ruptures; therefore, endoleaks are aggressively evaluated and treated if they persist beyond the 6-month follow-up, unless the aneurysm sac has shrunk. ${ }^{14,25,26}$

Because persistent T2Es are significant contributors to late adverse outcomes such as aneurysm rupture, conversion to open repair, aneurysm sac growth and the need for reintervention, several treatment options are available for the management of T2Es (Box 3). However, the management of T2Es is hotly debated because of diverse personal experience and beliefs concerning the long-term outcome of the various approaches. T2Es are complex vascular structures that contain an endoleak cavity, or nidus, with several feeding and draining vessels similar to an arterial venous malformation. Effective treatment requires complete obliteration of the nidus, with resulting permanent cessation of flow in all the vessels involved. Partial or incomplete elimination will lead to recurrence and continued risk of aneurysm growth and rupture. Thus, obliteration of T2Es can be challenging and requires advanced endovascular skills.

Transfemoral and translumbar embolization are the commonly used techniques in contemporary practice. ${ }^{16,27-31}$ Higher failure rates with femoral TAE compared to TLE $(80 \%$ vs. $8 \%)$ are believed to be due to embolization of a single vessel and failure to completely obliterate the central nidus and the feeding vessel(s) in the first attempt. Of interest, comparable success rates $\left(72 \%\right.$ vs. $78 \%$ ) have been reported ${ }^{16,32}$ when both the feeding artery and endoleak cavity are embolized. ${ }^{17}$

TAE involves retrograde catheterization using microcatheters with occlusion by coiling or embolic 


\section{Box 3. Management strategies for type II endoleak}

\section{Reintervention}

1. Transarterial embolization

2. Translumbar embolization

3. Transgraft embolization

4. Transcaval embolization

5. Transfemoral transsealing embolization

6. Open and laparoscopic ligation of the lumbar and mesenteric arteries

7. Laparotomy with plication of the endoleak source within the aneurysm sac

8. Total robotic ligation of the inferior mesenteric artery

9. Endograft explantation for continued growth after endovascular reintervention failure (8-10\% of cases)

\section{Preemptive/preventive intervention* (for} occluding potential sources of collateral inflow)

1. Placement of Onyx, thrombogenic absorbable sponge, polyurethane foam or fibrin glue concurrent to the deployment of the endograft

2. Selective preoperative embolization of large inferior mesenteric arteries ${ }^{\dagger}$

*Those who oppose the preemptive approach to type II endoleak (T2E) suggest such treatment is not warranted due to the low incidence of T2Es with aneurysm sac growth coupled with the risks and costs of preemptive treatment. The clot engineering concept for T2E prevention will lead to future research in the field of biomaterials and polymers. Preemptively occluding potential sources of collateral inflow has been widely accepted for some branch vessels such as the internal iliac artery (IIA). If the distal landing zone does not allow for a seal above the IIA (a common problem due to ectatic common iliac arteries associated with abdominal aortic aneurysm), occlusion of one IIA is commonly performed before endovascular aneurysm repair with use of coils or other occlusion devices like the Amplatzer ${ }^{\circledR}$ vascular plug (AGA Medical, Golden Valley, MN). Bilateral IIA occlusion, however, is avoided due to a high incidence of postoperative intractable buttock claudication.

${ }^{\dagger}$ The value of this approach has never been verified or adopted on a large scale. materials. Inflow and outflow vessels are embolized. In T2Es involving the internal mesenteric artery, the middle colic artery is selected through the superior mesenteric artery and retrograde access to the internal mesenteric artery is gained through the marginal artery. T2Es involving the lumbar arteries are accessed through retrograde cannulation of the iliolumbar arteries from the internal iliac arteries. ${ }^{17}$

During TLE, the aneurysm sac is directly punctured with a spinal needle under fluoroscopic or CT guidance while the patient is in the prone position, typically from a left paraspinal approach. Optimal needle entry, anatomical landmarks and depth can be predicted by CT imaging. The goal is to access the nidus of the endoleak, which can be confirmed by pulsatile flow. The endoleak nidus is then embolized with liquid agents or coils, similar to TAE. ${ }^{17}$

Repeat interventions are required in an estimated $2-20 \%$ of cases regardless of whether TAE or TLE was used, ${ }^{8,16,32,33}$ usually because the culprit vessels were not adequately identified or treated during the initial embolization. This statistic underscores the importance of complete obliteration of the nidus of the endoleak. ${ }^{17}$

The innovative transgraft embolization technique we've adopted allows a transarterial route, usually transfemoral, with predictable puncture of the endograft close to the nidus of the T2E. Utilizing a multifiber coronary laser rapid exchange atherectomy catheter consisting of optical fibers encased within a polyester shaft, ultraviolet energy is transmitted from the excimer laser system (CVX-300 ${ }^{\circledR}$, Spectranetics) to the endoprosthesis to photoablate the graft material. (Photoablation is the process by which energy photons cause molecular bond disruption without thermal damage to surrounding tissue.) Once access is gained to the aneurysm sac, a coronary microcatheter (Echelon 10, ev3 Endovascular) is advanced over a 0.014-inch coronary wire into the sac as close to the nidus as possible. The Echelon family of over-thewire microcatheters (nitinol braided design) is based on a unique technological platform that provides exceptional pushability and trackability and allows more flow in the guide catheter, which can be useful for angiographic injections. Insertion of the coronary microcatheter is then followed by the injection of 
liquid embolic agent Onyx 34 (ev3 Neurovascular), an ethylene-vinyl-alcohol copolymer dissolved in dimethyl sulfoxide (DMSO). Micronized tantalum powder is suspended in the liquid polymer/DMSO mixture to provide radiopacity. Onyx is therefore a premixed, radiopaque, injectable embolic agent that is not a glue, has no adhesive properties and solidifies through the process of precipitation. Precipitation is initiated when Onyx comes into contact with an aqueous solution (e.g. blood, body fluids, normal saline, water) and the solvent DMSO rapidly diffuses out of the polymer mass, thus causing in situ precipitation of a soft radiopaque polymeric embolus. Onyx is first slowly injected to displace the DMSO, and then the injection is continued at a slow, steady rate under optimal fluoroscopic control to avoid occlusion of nontarget vessels. The distance that Onyx travels before solidifying within the vasculature depends on a number of factors, including the flow rate in the vessel and the rate of injection. After completion of the injection, the microcatheter is removed by gently pulling during slight aspiration. Currently, Onyx is rapidly gaining increasing acceptance as a promising liquid embolic agent of choice for complete occlusion of the nidus of a $\mathrm{T} 2 \mathrm{E}$, a mandatory step in the reintervention technique.

Implementing TGE to treat the persistent T2E described here demonstrates the value of using a modified transarterial approach in locating and successfully eliminating the nidus of the endoleak while avoiding the more cumbrous TLE procedure. For this case, 1-year follow-up CTA showed regression of the aneurysm sac, indicative of complete T2E obliteration (Figure 4).

\section{CONCLUSION}

Even though endovascular aneurysm repair has emerged as the first-line management strategy in patients with infrarenal abdominal aortic aneurysm, reintervention after EVAR continues to be an important issue, primarily due to persistent type II endoleaks. The results of contemporary secondary interventions for management of T2Es (transarterial or translumbar embolization) are suboptimal due to incomplete embolization/elimination of the endoleak cavity or nidus. Transgraft embolization is an attractive treatment alternative to TLE or TAE because it allows for precise and predictable endovascular access to the nidus of the endoleak and a better embolization result. In our practice, TGE has completely replaced TAE and TLE. We are in the process of analyzing the results of this novel technique.

\section{Patient-Friendly Recap}

- Aneurysms that form around the aorta are usually repaired using stent grafts.

- Subsequent arterial leaks are a common complication of this endovascular repair.

- Successfully treating a persistent leak using traditional methods can be difficult due to nearby body structures.

- The authors report a novel endovascular technique called transgraft embolization, which delivers specialized liquid agents through microcatheters to effectively eliminate this type of endoleak.

\section{Acknowledgments}

The authors gratefully acknowledge Jennifer Pfaff and Susan Nord of Aurora Cardiovascular Services for editorial preparation of the manuscript and Brian Miller and Brian Schurrer of Aurora Sinai Medical Center for help with the figures.

\section{Conflicts of Interest}

None.

\section{REFERENCES}

1. Greenhalgh RM, Brown LC, Kwong GP, Powell JT, Thompson SG; EVAR trial participants. Comparison of endovascular aneurysm repair with open repair in patients with abdominal aortic aneurysm (EVAR trial 1), 30-day operative mortality results: randomised controlled trial. Lancet. 2004;364:843-8. CrossRef

2. Chaikof EL, Brewster DC, Dalman RL, et al. SVS practice guidelines for the care of patients with an abdominal aortic aneurysm: executive summary. J Vasc Surg. 2009;50:880-96. $\underline{\text { CrossRef }}$

3. Moll FL, Powell JT, Fraedrich G, et al. Management of abdominal aortic aneurysms clinical practice guidelines of the European Society for Vascular Surgery. Eur J Vasc Endovasc Surg. 2011;41 Suppl 1:S1-S58. CrossRef

4. Dangas G, O'Connor D, Firwana B, et al. Open versus endovascular stent graft repair of abdominal aortic aneurysms: a meta-analysis of randomized trials. JACC Cardiovasc Interv. 2012;5:1071-80. CrossRef

5. Veith FJ, Baum RA, Ohki T, et al. Nature and significance of endoleaks and endotension: summary of opinions expressed at an international conference. J Vasc Surg. 2002;35:1029-35. CrossRef 
6. Sidloff DA, Stather PW, Choke E, Bown MJ, Sayers RD. Type II endoleak after endovascular aneurysm repair. Br J Surg. 2013;100:1262-70. CrossRef

7. Ward TJ, Cohen S, Patel RS, et al. Anatomic risk factors for type-2 endoleak following EVAR: a retrospective review of preoperative CT angiography in 326 patients. Cardiovasc Intervent Radiol. 2014;37:324-8. CrossRef

8. Nolz R, Teufelsbauer H, Asenbaum U, et al. Type II endoleaks after endovascular repair of abdominal aortic aneurysms: fate of the aneurysm sac and neck changes during long-term follow-up. J Endovasc Ther. 2012;19:193-9. CrossRef

9. Dorffner R, Schoder M, Mostbeck G, Hölzenbein T, Thurnher $\mathrm{S}$, Lammer J. Inferior mesenteric artery as outflow vessel in endoleaks after abdominal aortic stent-graft implantation: 36-month follow-up CT study. Eur Radiol. 2001;11:2252-7. CrossRef

10. Jones JE, Atkins MD, Brewster DC, et al. Persistent type 2 endoleak after endovascular repair of abdominal aortic aneurysm is associated with adverse late outcomes. $J$ Vasc Surg. 2007;46:1-8. CrossRef

11. Tolia AJ, Landis R, Lamparello P, Rosen R, Macari M. Type II endoleaks after endovascular repair of abdominal aortic aneurysms: natural history. Radiology. 2005;235:683-6. CrossRef

12. Silverberg D, Baril DT, Ellozy SH, et al. An 8-year experience with type II endoleaks: natural history suggests selective intervention is a safe approach. J Vasc Surg. 2006;44:453-9. CrossRef

13. Baum RA, Carpenter JP, Golden MA, et al. Treatment of type 2 endoleaks after endovascular repair of abdominal aortic aneurysms: comparison of transarterial and translumbar techniques. J Vasc Surg. 2002;35:23-9. Erratum in: J Vasc Surg 2002;35:852. CrossRef

14. Rosen RJ, Thompson J. Endoleaks: a persistent problem. $O R$ Nurse. 2009;3:24-35. CrossRef

15. Sheehan MK, Ouriel K, Greenberg R, et al. Are type II endoleaks after endovascular aneurysm repair endograft dependent? J Vasc Surg. 2006;43:657-61. CrossRef

16. Sarac TP, Gibbons C, Vargas L, et al. Long-term follow-up of type II endoleak embolization reveals the need for close surveillance. J Vasc Surg. 2012;55:33-40. $\underline{\text { CrossRef }}$

17. Saqib NU, Charlton-Ouw KM, Azizzadeh A. Managing type II endoleaks. (Endovascular Today, February 2013). www. evtoday.com/2013/02/managing-type-ii-endoleaks. Accessed April 15, 2015.

18. Stavropoulos SW, Charagundla SR. Imaging techniques for detection and management of endoleaks after endovascular aortic aneurysm repair. Radiology. 2007;243:641-55. CrossRef

19. Cornelissen SA, Prokop M, Verhagen HJ, Adriaensen ME, Moll FL, Bartels LW. Detection of occult endoleaks after endovascular treatment of abdominal aortic aneurysm using magnetic resonance imaging with a blood pool contrast agent: preliminary observations. Invest Radiol. 2010;45:548-53. $\underline{\text { CrossRef }}$
20. Ohki T, Ouriel K, Silveira PG, et al. Initial results of wireless pressure sensing for endovascular aneurysm repair: the APEX Trial--Acute Pressure Measurement to Confirm Aneurysm Sac EXclusion. J Vasc Surg. 2007;45:236-42. CrossRef

21. Parsa CJ, Daneshmand MA, Lima B, Balsara K, McCann RL, Hughes GC. Utility of remote wireless pressure sensing for endovascular leak detection after endovascular thoracic aneurysm repair. Ann Thorac Surg. 2010;89:446-52. CrossRef

22. Milner R, De Rango P, Verzini F, Cao P. Are intrasac pressure measurements useful after endovascular repair of abdominal aortic aneurysms? J Vasc Surg. 2011;53:534-9. CrossRef

23. Lee K, Forbes TL. Current understanding of the significance and treatment of type II endoleaks. Italian Journal of Vascular and Endovascular Surgery. 2012;19:191-7.

24. Buth J, Harris PL, can Marrewijk C, Fransen G. The significance and management of different types of endoleaks. Semin Vasc Surg. 2003;16:95-102. CrossRef

25. Stavropoulos SW, Clark TW, Carpenter JP, et al. Use of CT angiography to classify endoleaks after endovascular repair of abdominal aortic aneurysms. J Vasc Interv Radiol. 2005;16:663-7. CrossRef

26. White GH, Yu W, May J, Chaufour X, Stephen MS. Endoleak as a complication of endoluminal grafting of abdominal aortic aneurysms: classification, incidence, diagnosis, and management. J Endovasc Surg. 1997;4:152-68. CrossRef

27. Sampram ES, Karafa MT, Mascha EJ, et al. Nature, frequency, and predictors of secondary procedures after endovascular repair of abdominal aortic aneurysm. J Vasc Surg. 2003;37:9307. $\underline{\text { CrossRef }}$

28. Sheehan MK, Barbato J, Compton CN, Zajko A, Rhee R, Makaroun MS. Effectiveness of coiling in the treatment of endoleaks after endovascular repair. J Vasc Surg. 2004;40:4304. CrossRef

29. Görich J, Rilinger N, Sokiranski R, et al. Embolization of type II endoleaks fed by the inferior mesenteric artery: using the superior mesenteric artery approach. $J$ Endovasc Ther. 2000; 7:297-301. CrossRef

30. Kasirajan K, Matteson B, Marek JM, Langsfeld M. Technique and results of transfemoral superselective coil embolization of type II lumbar endoleak. J Vasc Surg. 2003;38:61-6. CrossRef

31. Baum RA, Cope C, Fairman RM, Carpenter JP. Translumbar embolization of type 2 endoleaks after endovascular repair of abdominal aortic aneurysms. J Vasc Interv Radiol. 2001;12:111-6. $\underline{\text { CrossRef }}$

32. Stavropoulos SW, Park J, Fairman R, Carpenter J. Type 2 endoleak embolization comparison: translumbar embolization versus modified transarterial embolization. J Vasc Interv Radiol. 2009;20:1299-302. CrossRef

33. Aziz A, Menias CO, Sanchez LA, et al. Outcomes of percutaneous endovascular intervention for type II endoleak with aneurysm expansion. J Vasc Surg. 2012;55:1263-7. CrossRef

(C) 2015 Aurora Health Care, Inc. 